\title{
Uso dos recursos naturais: desafios das populações do entorno do Parque Nacional de Ubajara (CE)
}

Use of natural resources: challenges for the populations in the surrounding area of the Ubajara

National Park (CE)

\author{
Lourenço $^{1}$, B. F. M.; Caracristi ${ }^{2}$, I.
}

benelourenco@yahoo.com.br

\section{Resumo}

Este artigo pretende evidenciar o uso e a ocupação dos recursos naturais e suas consequências socioambientais para a população do entorno do Parque Nacional (Parna) de Ubajara (Ceará), no Planalto da Ibiapaba. O parque possui diferencial morfoclimático, estando inserido na floresta ombrófila aberta, que, segundo a Lei 11.428/2006, integra os remanescentes de Mata Atlântica. Historicamente, o Planalto da Ibiapaba integrou os ciclos produtivos de cana-de-açúcar, café e algodão no Ceará, nos séculos XIX e XX. Atualmente, tais ciclos têm sido substituídos pelo cultivo comercial da fruticultura e olericultura, viabilizado pelo uso intenso de insumo externo: esterco, adubação química com suplemento de NPK (nitrogênio, fósforo e potássio), pó de rocha, sementes híbridas e transgênicas e uso concentrado de agrotóxicos. O uso intensivo do solo para atividades agrícola, de pecuária extensiva e de extrativismo florestal predatório nos revela as ameaças e a vulnerabilidade da conservação. Na pesquisa qualitativa, ficou evidente que parte da população não reconhece a importância e o objetivo do Parna Ubajara. Torna-se evidente, assim, a importância da unidade de conservação para a preservação da natureza, apesar da complexa relação estremecida da população com o parque. A essa reflexão, associam-se novas práticas socioambientais na busca da recuperação dos recursos naturais degradados, estimulando mudanças na prática da agricultura familiar.

Palavras-chave: natureza; Ibiapaba; conservação

\begin{abstract}
This article aims at evidencing the use and the occupation of natural resources and its social-environmental consequences for the population of the National Park (Parna) of Ubajara (Ceará), in the Ibiapaba Plateau. The park has a morph-climatic differential, being inserted in the open ombrophylous forest that, according to Law n. 11.428/2006, integrates the remainders of the Atlantic Rainforest. Historically, the Ibiapaba Plateau integrated the productive cycles of sugar cane, coffee and cotton in Ceará in the 19 th and 20 th centuries. Nowadays, such cycles have been replaced by the commercial harvest of fruit and vegetables farming, enabled by the intense use of external input: manure, chemical fertilization with a NPK supplement (nitrogen, phosphorous and potassium), rock powder, hybrid and transgenic seeds and concentrated use of agrochemicals. The intensive use of the soil for agricultural activities, extensive stock-breeding and forest predatory model reveals the threats and the conservation vulnerability. In the qualitative analysis, it became evident that part of the population does not recognize the importance and the unit of conservation for the preservation of nature, despite the complex relationship between the population and the park. To this reflexion, new social-environmental practices in the search for the recovery of degraded natural resources are associated, stimulating changes in the practice of family agriculture.
\end{abstract}

Keywords: nature; Ibiapaba; conservation

\section{INTRODUÇÃO}

O presente artigo pretende evidenciar o uso e a ocupação dos recursos naturais e as consequências socioambientais para a população local do entorno do Parque Nacional (Parna) de

\footnotetext{
1 Benedito Francisco Moreira Lourenço é mestrando em Geografia pela Universidade Estadual Vale do Acaraú (UVA), Sobral-CE, Brasil.

${ }_{2}$ Isorlanda Caracristi é professora Dra. dos Cursos de Graduação e Mestrado Acadêmico em Geografia da Universidade Estadual Vale do Acaraú (UVA), Sobral-CE, Brasil. E-mail: icaracristi@hotmail.com
} 
Ubajara-Ceará, pois, sendo unidade de conservação de proteção integral, não permite a presença da população no seu interior e o uso de recursos naturais de forma direta. Tais medidas têm motivado conflitos e alterado modo de vida das populações e a relação entre sociedade e natureza.

Os aspectos legais da territorialização no Brasil e a relação com as unidades de conservação (UC's) nos apresentam algumas reflexões, sobretudo a respeito dos conceitos de populações tradicionais e de população local, definições de que trataremos aqui.

Rebelo (2014) nos apresenta o aspecto jurídico para contemplar o conceito de população tradicional. Segundo o autor, o termo não possui homogeneidade jurídica, embora tenha profunda similaridade sociológica, antropológica. $\mathrm{Na}$ categoria de "populações tradicionais" estão os quilombolas $^{3}$, com propriedade da terra; e os indígenas, com posse permanente.

Define-se também em lei: as quebradeiras de coco, no extrativismo do babaçu; os castanheiros e seringueiros na Amazônia; e os pescadores como categoria social, grupos coletivos. Os grupos sociais citados não recebem atenção da legislação ambiental brasileira, embora o Sistema Nacional de Unidades de Conservação (SNUC) os reconheça. Na prática, contudo, torna-os invisíveis, o que normalmente tem gerado conflito e agravado a vulnerabilidade socioambiental, equiparando-os, no "abismo comum", aos degradadores da natureza, algo inerente no atual modelo de sociedade que acumula riqueza, espolia trabalho e recursos naturais. A respeito dessa contradição presente na política de conservação, Ennes (2014, p. 247) considera:

O novo circuito de relações surgido com a implementação das UCs tem produzido a violência simbólica contra os moradores mais pobres, a exemplo dos donos e trabalhadores de olarias, em especial sob a forma da ilegalidade ambiental e invisibilização social.

Em seus 16 anos de existência, o SNUC não conseguiu superar as dificuldades na gestão dos territórios das UC's, criados com pouco ou sem envolvimento da população, sobretudo, quando se trata de unidade de proteção integral. As posturas autoritárias, de exclusividade preservacionista, têm excluído a participação das populações locais na gestão. Nesse cenário, insere-se o Parque Nacional de Ubajara (CE), que, apesar de ter sido criado em 1959, ainda não resolveu os problemas socioambientais decorrentes da criação da referida UC.

3 Quilombolas: grupos étnico-raciais com trajetória histórica que possuem identidade como remanescentes de escravos, reconhecidos no Brasil a partir da Constituição Federal, no Ato das Disposições Constitucionais Transitórias (ADCT). A institucionalização da política quilombola é legitimada conforme art. $2^{\circ}$, caput, do Decreto $\mathrm{n}^{\circ} 4.887 / 2003$, que dispõe: "consideram-se remanescentes das comunidades dos quilombos, para os fins deste Decreto, os grupos étnico-raciais, segundo critérios de autoafirmação, com trajetória própria, dotados de relações territoriais específicas, com presunção de ancestralidade negra relacionada com a resistência à opressão histórica sofrida". 


\subsection{Característica física do entorno do Parna Ubajara}

O Parna Ubajara apresenta uma particularidade por sua localização na cuesta da Ibiapaba, no Planalto da Ibiapaba, também chamada de Serra da Ibiapaba e Serra Grande. O parque possui diferencial morfoclimático, com mata úmida chamada popularmente de "cinturão verde", vegetação de características da Floresta Ombrófila $\mathrm{Aberta}^{4}$, de clima ameno, altitude acima de 800 metros e reserva hídrica decorrente da bacia sedimentar paleo-mesozóica. O solo apresenta características pedológicas diferenciadas. Para Sousa (2005), ocorre uma predominância dos latossolos, que apresentam fertilidade limitada e sensibilidade aos processos erosivos em decorrência do modelo de produção, que adota práticas e técnicas de manejo degradantes.

De acordo com Araújo (2004), o Planalto da Ibiapaba apresenta deposição sedimentar, na forma de cuesta com relevo dessimétrico, tendo o reverso inclinado para o oeste no limite com o estado do Piauí. Além disso, apresenta o front variável, com declive variável de $25^{\circ}$ a $35^{\circ}$ na forma de cornija, com vertente para o lado oeste do Estado do Ceará.

Outra parte do Parna Ubajara situa-se na depressão sertaneja, a unidade geomorfológica de maior expressão do Ceará de relevo (pediplano) integra parte dos municípios de Frecheirinha, Ibiapina, Tianguá e Ubajara, com altitude inferior a 400 metros, clima semiárido, com uso intensivo de solo pela atividade agrícola, pecuária extensiva e o extrativismo florestal predatório. A caatinga apresenta os seguintes estágios florísticos: estrato arbóreo, com espécies que variam entre 8 e 12 metros de altura; o arbustivo e subarbustivo, com indivíduos de 2 a 5 metros; e o estrato herbáceo, com variada biodiversidade, com espécies de ciclo anual e efêmero.

Segundo o IBAMA (2002), a área do entorno do Parque Nacional de Ubajara está inserida na depressão sertaneja, com vegetação de transição, potencialmente mais vigorosa, chamada de mata seca, uma vegetação mesófila, de fisionomia associada aos ecossistemas da Mata Atlântica, de acordo com a resolução 10/1993, art. $4^{\text {o }}$ do Conselho Nacional de Meio Ambiente (Conama), ocupando a encosta da Serra da Ibiapaba. Entre as espécies arbóreas mais representativas que ocupam a depressão sertaneja, destacam-se as seguintes: aroeira (myracrodruon urudeva), paubranco (Auxema oncocalyx), pau branco louro (A. glazioviana), freijorfe (Cordia trichotoma), sabiá (Mimosa caesalpinifolia), jurema preta (M. tenuiflora), jucá (Caesalpinia férrea), pau d'arco roxo (Tabebuia impetiginosa), cumaru (Amburana cearenses), pereiro (Aspidosperma pirifolium), imburana de cambão (Bursera leptophloeos), canafístula (Senna excesa), espinheiro (Acacia

\footnotetext{
$4 \quad$ Remanescentes de Mata Atlântica Lei 11.428 de 2006. O referido bioma é composto por um conjunto de tipo de vegetação e ecossistemas associados: manguezais, restingas, florestas de baixadas, tabuleiros e encraves nas regiões sul, sudeste, Centro Oeste e Nordeste (MMA, 2010) Segundo o IBGE, o Ceará 30,93\% dos fragmentos originais considerados pela Portaria do MMA 923/01/2007, com áreas prioritárias a conservação, uso sustentável e repartição dos benefícios da biodiversidade. (MMA, 2010 p. 252).
} 
glomerosa), aroeira preta (Astronium urundeuva), faveleiro (Cnidosculus phylacanthus), mandacaru (Cereus jamacaru), mandacaru facheiro (Pilocerus squamosus), marizeira (Calliandra spinosa) e angico (Anadenanthera colubrina).

Devido aos constantes manuseios predatórios da flora, a caatinga apresenta estágio sucessório, com predominância de espécies pioneiras dominantes, indicadoras de áreas degradadas em decorrência dos intensos desmatamentos e do uso do fogo.

$\mathrm{Na}$ área de influência do Parque Nacional de Ubajara, conforme apresenta o IBAMA (2002), a depressão sertaneja apresenta uma caatinga arbórea e arbustiva/subarbustiva. A caatinga arbórea tem sido descaracterizada pelos intensos desmatamento e o uso do fogo, como mostra a figura 1, que apresenta a prática da produção de carvão através da queima da madeira na caieira ${ }^{5}$, sem licença ambiental e plano de manejo, com transporte efetuado no lombo de jumento pela trilha portão (Araticum-Ubajara). Como mostra a figura 2, o transporte ocorre pela ladeira do Urucum (Ibiapina). A comercialização do carvão como produto considerado ilegal é um dos principais conflitos socioambientais que têm dificultado o relacionamento entre a população e a gestão da unidade de conservação.

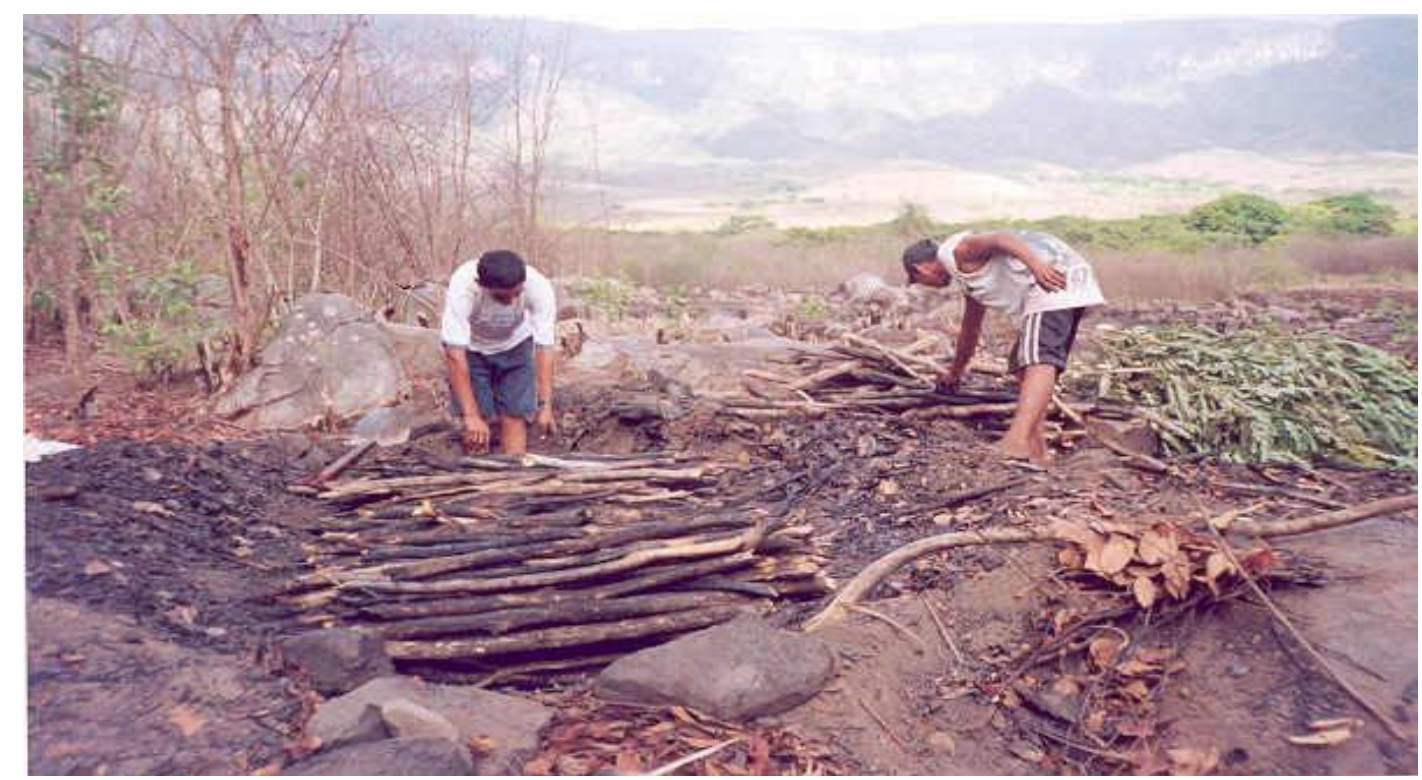

Figura 1: Preparo da lenha para produção de carvão. Fonte: Vilma Araújo (janeiro de 2003)

Historicamente, o Planalto da Ibiapaba integrou os ciclos produtivos do Ceará com a canade-açúcar, café e algodão nos séculos XIX e XX. Atualmente a política do ciclo produtivo tem sido

\footnotetext{
5 Caieira - Uma vala chamada de trincheira, para enterrar madeira para queima no chamado de formo bacurau. A produção de carvão dessa forma é extremamente degradante do ponto de vista social no manuseio e pela perda do produto final (carvão).
} 
substituída pelo cultivo comercial da fruticultura: tangerina, maracujá, abacate, manga, banana e a olericultura.

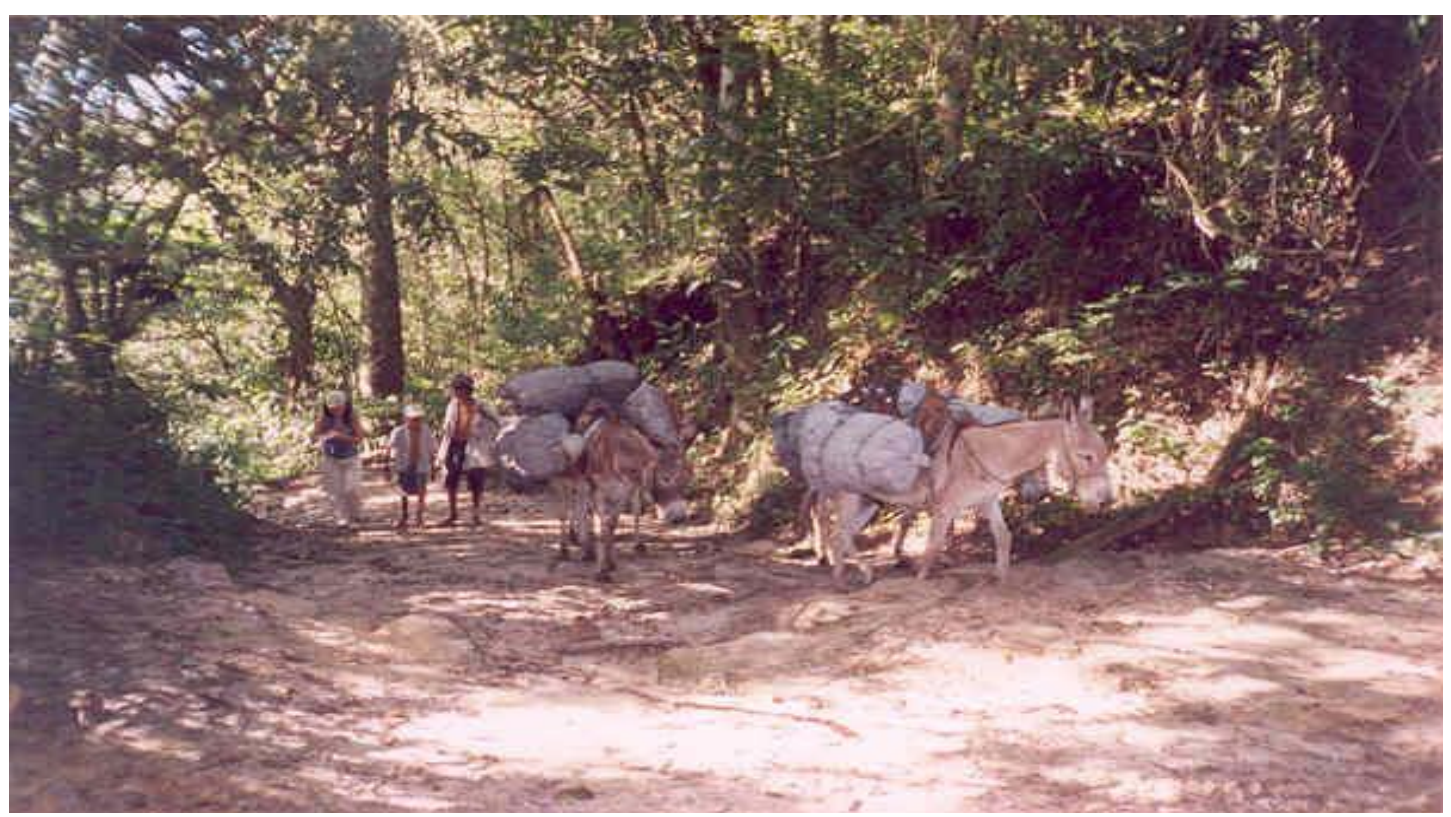

Figura 2: Transporte de carvão no interior do parque para comercialização - Ubajara.

Fonte: Vilma Araújo (janeiro 2003)

Nos últimos 15 anos do XXI, estabeleceram-se grandes cultivos em escala para o fornecimento ao mercado de exportação, os "agribusiness", com a presença de grupos econômicos como a Reijers na produção de flores e a Empresa Nutrilite na produção do concentrado de acerola para produção do suplemento alimentar vitamínico C.

O referido modelo agrícola tem sido sustentado na prática do uso de insumo, com alta carga de input externo: esterco, adubação química com suplemento de NPK (nitrogênio, fósforo e potássio), pó de rocha, sementes híbridas e transgênicas e uso concentrado de agrotóxicos, o que tem gerado a contaminação do lençol freático, comprometendo a qualidade da água subterrânea e a qualidade dos produtos agrícolas.

\subsection{Zona de Amortecimento}

O Parque Nacional de Ubajara localiza-se na porção Noroeste do Estado do Ceará, integra o alto curso da região hidrográfica do Coreaú, integrando parte dos municípios de Frecheirinha, Tianguá e Ubajara, distando $300 \mathrm{~km}$ da capital do estado, Fortaleza, por via rodoviária, com acesso pela BR-222 e rodovia CE-187. A área de estudo compreende a localidade de Caiçara, município de Ibiapina, zona de amortecimento na latitude $3^{\circ}$ e $46^{\prime}$ e longitude $40^{\circ}$ e $54^{\prime}$, inserida na depressão 
sertaneja periférica ocidental. Segundo a lei 9.985 de 18/06/2000 do SNUC no artigo $2^{\circ}$, inciso XVIII, estabelece como zona de amortecimento (conhecida como zona de transição ou área de “amortecimento da unidade de conservação, área de restrição específica, com o propósito de minimizar os impactos negativos sobre as áreas protegidas de proteção integral"). A partir da Resolução No 428 de 17/12/2010, o entorno passa a ser denominado de "área circundante", com área de $3 \mathrm{~km}$. No entanto, o presente estudo adota os limites do artigo $2^{\circ}$ da lei $\mathrm{N}^{\circ} 9.985$ de 18/06/2000 do SNUC.

\section{3. Área de estudo: Caiçara (Ibiapina)}

Não há registros históricos e científicos da localidade Caiçara. Com base nos relatos dos moradores, identificamos algumas informações que integram a história. Segundo a liderança local ${ }^{6}$ entrevistada, a história da comunidade nos remete ao século passado (1958). Uma família de comboieiro $^{7}$, procedente de Jaibaras, Sobral (CE), chegou ao local e resolveu ficar por alguns dias. Devido à seca da época, resolveu morar de agregado e, posteriormente, comprou uma parte do terreno que deu origem à comunidade. A referida localidade dá nome ao riacho que forma o Rio Coreaú. A população local é formada por agricultores familiares e posseiros, integrando o município de Ibiapina, na depressão sertaneja, fronteira com o município de Mucambo, que disputa a população situada na fronteira, caracterizando-se no verdadeiro descaso com a população, que disputa os atendimentos das políticas públicas.

\section{METODOLOGIA}

A pesquisa estabelece a localidade de Caiçara como área de estudo por dois fatores: a) trata-se do aglomerado populacional mais afastado do perímetro do Parna Ubajara, inserido na zona de amortecimento; b) e conta com número significativo de moradores que enfrentam problemas socioambientais, a ilegalidade relacionada com a exploração dos recursos florestais em função da produção de carvão com transporte e comércio ilegal. Outro aspecto é a existência do sítio Pindobal, formado por famílias que moravam antes da criação do Parna Ubajara e, por ocasião da criação do Parque, foram expulsas.

Os procedimentos metodológicos da pesquisa envolvem levantamento bibliográfico, discussão dos conceitos geográficos de natureza, recursos naturais, território, gestão e conflitos ambientais, análise de acervo cartográfico e revisão dos seguintes documentos e relatórios técnicos:

\footnotetext{
${ }^{6}$ João Paulo Lima Almeida, agricultor familiar e liderança local.

${ }^{7}$ Comboieiro: condutor de comboio de jumentos que transportavam mercadoria antes da evolução do sistema transporte de veículo automotor.
} 
plano de manejo do Parque Nacional de Ubajara: encartes 1, 2, 3 e 4; documentos institucionais, como leis, decretos; teses e artigos científicos; mapas/cartas temáticas; fotografias horizontais e aéreas; e imagens de satélite. No trabalho de campo, incluem-se reuniões com lideranças e representantes de instituições. Ainda se incluem nas etapas da pesquisa visitas às localidades que integram a microrregião de Caiçara (Fechado, Campo de Dentro, Tamundé, Bananeira e Pindobal), totalizando 250 moradores. Foram realizadas conversas programadas a partir de entrevistas semiestruturadas com moradores, agentes de saúde, professores e agricultores, com a aplicação de 25 questionários que indagaram sobre a visão e compreensão dos moradores sobre a importância do Parna Ubajara, as dificuldades e ameaças, resistência e a vulnerabilidade da conservação.

O segundo grupo da pesquisa inclui as seguintes instituições: Associação Comunitária de Caiçara, Secretaria Municipal de Agricultura e Meio Ambiente de Ibiapina e Ubajara, chefia do Parna Ubajara, Sindicato dos Trabalhadores e Agricultores(as) de Ibiapina, Cooperativa Agroextrativista familiar da Ibiapaba e Norte Cearense, Fundação CIS que responderão questionários sobre suas atuações na educação ambiental, como compreende a política de conservação e a relação com o Parna.

Destacamos o público do Sítio Pindobal pela simetria com as análises de Arruda (1997), quando afirma que os parques nacionais integram um modelo de gestão com controle e poder público com o qual enfrentam dificuldades, desafios e uma dicotomia conflitante entre o ser humano e a natureza.

[...] supõe que as comunidades locais são incapazes de desenvolver um manejo mais sábio dos recursos naturais [...] as populações resistem e permanecem com suas necessidades de exploração dos recursos naturais inerentes a seu modo de vida e sobrevivência raramente são reconhecidas (ARRUDA, 1997, p.7).

A pesquisa ainda apresenta, de forma qualitativa, resultados da política de conservação, ações mitigadoras dos efeitos da degradação a partir de inciativas realizadas por instituições que atuam na área e pelos moradores (agricultores familiares, extrativistas), bem como a atuação da política de conservação, dos projetos de fomento e de educação ambiental, realizados pelo poder público e pela sociedade civil.

\section{RESULTADOS E DISCUSSÃO}

\subsection{O Parque visto pelos moradores e as consequências da relação homem-natureza}


Segundo Vallejo (2005), em sua tese de doutorado, a criação dos espaços protegidos potencializam processos de desterritorialização de grupos sociais e populações tradicionais. O autor relata que essa prática também se efetivou na África, com governos locais que enfrentaram antipatia das populações locais na definição do conceito de proteção da vida selvagem. Outros autores afirmam que o modelo de conservação como prática e filosofia exógena - baseada na concepção de que a população é parceira, e não coautora da conservação - tem tornado insatisfatório o principal objetivo da conservação da natureza.

Os percalços vivenciados na relação dos moradores com o Parna Ubajara atualmente confirmam uma simetria com o que aponta Araújo (2002), que considera que os moradores foram desterritorializados durante a criação da unidade de conservação. Araújo relata que 133 famílias moravam na área do Parna Ubajara antes da criação, em 1959, tendo o processo de desapropriação bastante lento e gerido de forma autoritária, estendendo-se até 1975.

As desconfianças na relação com o Parna Ubajara ainda são evidentes. Na visita aos moradores, na elaboração de entrevista e aplicação do questionário, um morador recusou-se a responder as perguntas da pesquisa, sendo na oportunidade orientado por outra pessoa da residência a não responder, afirmando: “Tu não responde essa entrevista, pois querem te encalacrar".

Quanto à relação sociedade-natureza predomina a agricultura tradicional, com a prática de abatimento predatório da caatinga arbórea, através da prática do desmatamento e queimada, transformando a paisagem da caatinga arbustiva, com o domínio de espécie pioneira de solos pobres. As áreas apresentam solos com limitações físicas e químicas para uso agrícola, sendo extremamente usado, ano após ano, sem que haja pousio, sendo exposto a grande insolação e com limitação hídrica decorrente da localização no semiárido.

Tanto o Ibama (2000), através do Plano de manejo do Parna Ubajara, como Araújo (2002), em sua dissertação de mestrado "O entorno do Parque Nacional de Ubajara-CE: caracterização socioambiental do distrito de Araticum”, afirmam que a população não entende a importância e o objetivo do Parna Ubajara. A autora (2002, p. 60) afirma que "a maioria dos antigos moradores guarda grandes mágoas, pela forma como foi conduzido o processo de desapropriação das terras. Aliás, muitas pessoas ainda temem perder suas terras para o IBAMA”.

Após 58 anos, é importante analisar o que pensam os moradores sobre o Parna Ubajara. Entre as informações, relatamos depoimentos de pessoas pesquisadas:

[...] o parque é uma área destinada à proteção dos animais silvestres; com a criação do Parque estabeleceu se a proibição ao desmatamento, abertura de roçados na "lombada" e da caça; atualmente os animais estão sendo protegidos, circulam livre nos ambientes, outros 
animais como as onças ameaçam os animais criados caprino e ovinos dos moradores das áreas do entorno ${ }^{8}$.

Os moradores mais esclarecidos ${ }^{9}$ apresentam uma versão da importância do Parque, como sendo o potencializador do turismo, sobretudo para o município de Ubajara, algo que não ocorreu com os demais municípios, visto que o turismo na Ibiapaba tem foco na gruta, tendo como atrativo o bondinho. A referida estratégia não efetiva distribuição de renda, visto o serviço de hotelaria com alto custo que se concentra na cidade, tornando seletiva a demanda turística.

\section{CONSIDERAÇÕES FINAIS}

Torna-se necessário reconhecer a existência das populações tradicionais e das populações locais tratadas neste trabalho, que, mesmo antes das concepções e institucionalidade do que chamamos de áreas protegidas, já praticavam o manejo da biodiversidade e a produção de conhecimento empírico. São evidentes os indícios de que a criação do Parna Ubajara tenha provocado alterações no cotidiano das famílias, desânimo nas comunidades com mudanças na autoestima, descrédito da política de conservação e das ações de educação ambiental. Em razão disso, as comunidades mais distantes da UC não reconhecem uma relação de importância da conservação, não demonstrando mudanças práticas no cotidiano da população.

A localidade Caiçara é vista pelos moradores como lugar de carência e dificuldades, abandono, com pobreza que aflige boa parte da população, devido à falta de opção de trabalho, sendo disputada pelo poder público através do limite municipal com Mucambo-Ibiapina. Parte considerável dos moradores vive da atividade extrativista ou da agricultura de subsistência. Não há atividade econômica adaptada à realidade local que possa contribuir para minimizar o empobrecimento, visto que o extrativismo vegetal e mineral é considerado ilegal e irregular sem ausência de licença ambiental com a anuência do Instituto Chico Mendes de Conservação da Biodiversidade (ICMBio).

Diante disso, percebemos a importância da unidade de conservação para preservação da natureza, apesar da complexa relação estremecida da população com a UC. No entanto, o parque pode potencializar iniciativas ecológicas, educativas e de resultados econômicos que envolvam iniciativas de distribuição de renda a partir da participação da população.

Depoimento de Luiz Lima Ramos.

João Paulo Lima Almeida e Fernando Tadeu. 


\section{REFERÊNCIAS}

ARAÚJO. V. T. O entorno do Parque Nacional de Ubajara-CE: características socioambientais do distrito de Araticum. UFC, CE. 2004.

ARAÚJO, J. M.; ARRUDA, D. B. Prática de sustentabilidade no semiárido nordestino: direito no desenvolvimento econômico sustentável. Veredas do direito, Belo Horizonte, V. 16, 2011.

ARRUDA, R. Populações tradicionais e a proteção dos recursos naturais em unidades de conservação. Ambiente \& Sociedade Ano II, No 5, PUC, São Paulo. 1999.

ENNES, M. A. Meio ambiente e pobreza entre populações não tradicionais Unissinos 2014, Revista Ciências Sociais.

IBAMA. Plano de Manejo - Parque Nacional de Ubajara. Encartes 1,2,3 e 4. Brasília: Governo Federal. 2002.

REBELO, F. P. Aspectos legais da territorialização no Brasil: algumas reflexões sobre o conceito de populações tradicionais. Canoas: Unisalle, 2014. www.revistas.unisalle.edu.br.

RIBEIRO, S C.; SOUZA, A.B;BESERRA, T. M. Características geoambientais do Planalto sedimentar da Ibiapaba - uma ilha de refúgio. I Simpósio de Geografia Física do Nordeste, Caderno de Cultura e Ciência Vol. 2. URCA, (CE) 2007.

SOUZA, M J.N; OLIVEIRA, V.P. V. Os enclaves úmidos e subsumidos do Semiárido do Nordeste Brasileiro. Fortaleza: Mecator, UFC, 2006.

SOUZA, M. J N; LIMA, F. A. M; PAIVA, J. B. Compartimentação topográfica do Estado do Ceará. Fortaleza: UFC, 1979.

VALLEJO, L. R. Políticas púbicas e Conservação ambiental: territorialidades em conflitos nos Parques estaduais da Ilha Grande, da Serra da Tiririca e do Desengano (RJ). 2005. UFF. RJ. Tese de doutorado.

\section{AGRADECIMENTOS}

Ao Conselho Nacional de Desenvolvimento Científico e Tecnológico, pela bolsa de mestrado que possibilitou o desenvolvimento da pesquisa que resultou neste artigo.

Recebido em: 14/08/2016

Aceito para publicação em: 01/10/2016 